\title{
Article \\ A Randomized Controlled Trail for Comparing LED Color Temperature and Color Rendering Attributes in Different Illuminance Environments for Human-Centric Office Lighting
}

\author{
Sujung Lee and Heakyung C. Yoon *
}

check for

updates

Citation: Lee, S.; Yoon, H.C. A Randomized Controlled Trail for Comparing LED Color Temperature and Color Rendering Attributes in Different Illuminance Environments for Human-Centric Office Lighting. Appl. Sci. 2021, 11, 8313. https:// doi.org/10.3390/app11188313

Academic Editors: Tran Quoc Khanh, Vinh Quang Trinh and

Sebastian Babilon

Received: 10 August 2021

Accepted: 3 September 2021

Published: 8 September 2021

Publisher's Note: MDPI stays neutral with regard to jurisdictional claims in published maps and institutional affiliations.

Copyright: (c) 2021 by the authors. Licensee MDPI, Basel, Switzerland. This article is an open access article distributed under the terms and conditions of the Creative Commons Attribution (CC BY) license (https:/ / creativecommons.org/licenses/by/ $4.0 /)$.
School of Architecture, Hongik University, 94 Wausan-ro, Mapo-gu, Seoul 04066, Korea; leesujung999@gmail.com * Correspondence: yoonh@hongik.ac.kr; Tel.: +82-(2)320-3030

\begin{abstract}
In this study, two experiments were conducted to investigate the effects of the color rendering index (CRI) and correlated color temperature (CCT) of light-emitting diode (LED) lighting on office user acceptance and to explore the proper color attributes for human-centric office lighting. Experiment 1 had four LED lights, with two levels for the CRI (CRI $<80$ : 79, 76; or CRI $\geq 80$ : $83,84)$ and CCT $(3000 \mathrm{~K}$ or $6500 \mathrm{~K})$ at 300 lux. In experiment 2 , there were four LED lights, with several levels for the CRI (CRI < 80: 78; or CRI $\geq 80$ : 87, 83) and CCT $(3000 \mathrm{~K}$ or $6500 \mathrm{~K})$ at 500 lux. Ninety-six participants in experiment 1 and ninety-four participants in experiment 2 performed a reading task. The results in experiment 1 and experiment 2 showed that LEDs with lower CRI values at warm color temperatures were rated as more acceptable than LEDs with higher CRI values at warm color temperatures. However, the positive effect extended to LEDs with higher CRI values at cool temperatures but not to LEDs with lower CRI values at cool temperatures. Therefore, the findings are that LEDs with lower CRI values at warm color temperatures and LEDs with higher CRI values at cool temperatures provide the right level of color attributes for office lighting.
\end{abstract}

Keywords: human-centric lighting (HCL); color rendering index (CRI); correlated color temperature (CCT); color attribute; office spaces

\section{Introduction}

The Commission internationale de l'éclairage (CIE) [1] has proposed integrative lighting. The term "human-centric lighting" (HCL) carries a similar meaning. It specifically integrates both visual and non-visual effects and produces physiological and psychological benefits for people. Houser et al. [2] outlined human-centric lighting that can be designed by manipulating four lighting variables - the light level, light spectrum, spatial pattern, and temporal pattern - in the built environment. Light stimulus is processed in visual and non-visual pathways and affects human visual, circadian, neuroendocrine, and neurobehavioral responses. The visual pathway involves a process where light is incident on rods and cones, whereas in the non-visual pathway light is incident on intrinsically photosensitive retinal ganglion cells (ipRGCs) [3-5]. There are two approaches to quantify the non-visual stimulation of light [6-9]. The measurement based on the spectral response of the photopigments in the cones, rods, and ipRGC photoreceptors measures the melanopic equivalent daylight illuminance (EDI), while the measurement based on melatonin suppression measures the circadian stimulus (CS). Many groups have worked on standardizing HCL evaluation criteria by considering the melanopic effects of ocular light in human-centric lighting [10-13]. Numerous attempts have been made to develop light-emitting diode (LED) spectral power distributions (SPDs) for human users in the HCL framework [14,15]. For LED office lighting, Islam et al. [16] and Dangol et al. [17] showed that color perception is related to the degree of acceptance by users, which can be assessed on scales of acceptable-unacceptable or like-dislike. The more subjects who judge a light source to be acceptable, the better the color quality is. 
The color qualities of lighting are characterized by two attributes: the color rendition properties and the color appearance of light sources [18]. The color rendition property of a light source is measured by the general color rendering index (CRI) Ra [19]. The color appearance of a light source is quantified by its correlated color temperature (CCT) [20]. The CRI recommendations are described as the minimum values for workplaces and different types of work. For example, the CRI value for offices should be greater than 80 [20-22]. The CCT recommendations represent warm color as below $3300 \mathrm{~K}$, intermediate color as between $3300 \mathrm{~K}$ and $5300 \mathrm{~K}$, and cold color as above $5300 \mathrm{~K}$ [21,22]. A few studies have been conducted on CCT levels for offices. Among them, Juslén [23] and Manav [24] suggested that the appropriate CCT levels for work and study are in the range from $4000 \mathrm{~K}$ to $5000 \mathrm{~K}$, while Wang et al. [25] proposed that they should be between $4500 \mathrm{~K}$ and $6500 \mathrm{~K}$.

The CIE has reported that the CRI has several shortcomings for evaluating the color rendition properties of LED lighting [26]. The CRI is a single arithmetic mean value, and this cannot predict the color appearance of an individual object's color. Thus, the CRI is inaccurate and incomplete. There is also an additional limitation that is inherent to color fidelity. Measures of color fidelity only predict the average magnitude of color difference and provide no information about the direction of change. To address the limitations and bring in additional information to evaluate color rendition, the Illuminating Engineering Society of North America (IESNA) and the American National Standards Institute (ANSI) published ANSI/IES TM-30-15: IES Method for Evaluating Light Source Color Rendition in 2015 and then, in 2020, the updated ANSI/IES TM-30-20 (commonly referred to as TM-30) [27].

Psychophysical studies have shown that LED lights that can increase the relative gamut area in comparison to the reference light source tend to be favored $[16,28]$. Islam et al. [16] investigated user preference and acceptance under LED lights that present the ability to saturate or de-saturate different colors in an office environment. They found that LED lights with higher values in the color quality scale (CQS), gamut area scale (Qg), CQS color preference scale (Qp), and gamut area index (GAI) were preferred and more accepted by subjects than LED lights with lower values in the Qg, Qp, and GAI. Wei et al. [28] compared two LED lamps, blue-pumped LED (BP-LED) lamps and BP-LED lamps that had diminished yellow emission (YD-LED), to explore user preference and found that the YD-LED was preferred.

Spatial brightness, which is defined as an attribute of a visual sensation, can be assessed on scales of dim-bright [29-31]. Some research has shown that brightness perception increases as the CCT of LED lights increases [32,33], while other research has found that an increase in the CCT of LED lights does not necessarily increase brightness perception $[34,35]$. These studies found that differences in brightness perception may occur at different CCT levels. Additionally, Wei et al. [28] found that, at the same CCT levels, YD-LED lights were perceived to be brighter than BP-LED lights. Islam et al. [16] also found that LED lights with higher $\mathrm{Qg}, \mathrm{Qp}$, and GAI values were perceived to be brighter than those with lower $\mathrm{Qg}$, Qp, and GAI values. These results demonstrate that brightness perception can be different at the same CCT levels.

LED lighting can provide a wide range of color aspects with different color rendition and CCT levels. This results in very different user acceptance responses. Therefore, this study investigated the effects of the CRI and CCT of LED lights on user acceptance and thereby proposes appropriate color attributes for HCL in offices. User acceptance factors were measured in terms of preference, visual comfort, readability, satisfaction, and self-reported productivity, all of which are related to work performance in offices. The illuminance recommended for offices by the IESNA [21] and the BAuA [22] is 500 lux, while that recommended by the Korean Agency for Technology and Standards (KATS) [36] is in the range of 150-300 lux. For LED office lighting, past psychophysical experiments were conducted under a single illuminance level between 150 and 300 lux $[37,38]$. 


\section{Methods}

\subsection{Experimental Setup}

The dimensions of our test room were length $=3.5 \mathrm{~m}$, width $=3.5 \mathrm{~m}$, and height $=2.45 \mathrm{~m}$, as shown in Figure 1 . A table and four chairs were centrally placed. The indoor temperature was kept at $22-23^{\circ} \mathrm{C}$. A blackout curtain was fitted to block the effects of external natural light. The work surface height was about $0.75 \mathrm{~m}$ from the floor and $1.65 \mathrm{~m}$ away from the light source.

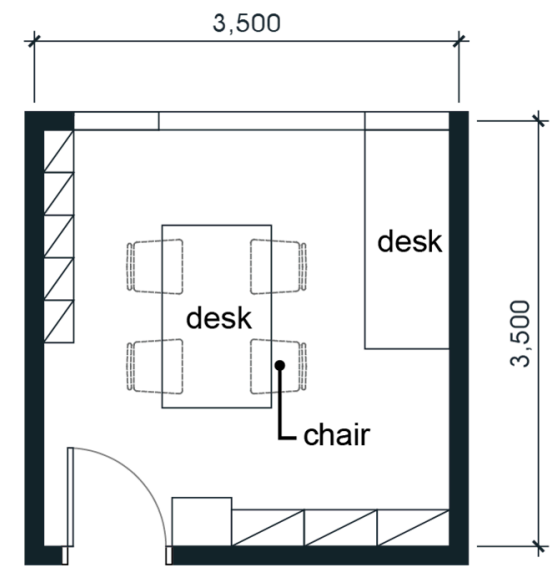

(a)

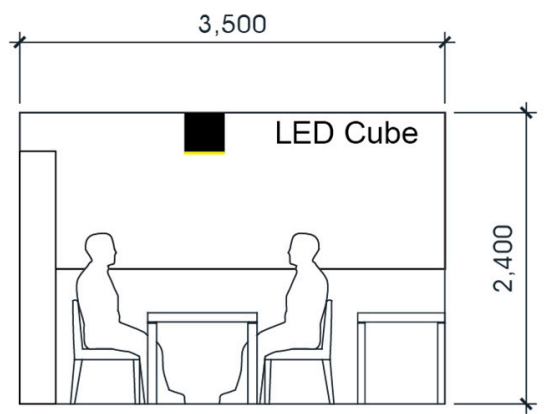

(b)

Figure 1. Experimental setup: (a) plan; (b) section.

\subsection{Lighting Settings}

We used a multi-channel LED lighting system (Thouslite) in a cube shape of $30 \times 30 \times 21 \mathrm{~cm}$. The LED lighting contained eleven independently controlled LED channels. The system was controlled with LED Navigator-LC V6.3.2 software for spectral tuning, and it was switched on $30 \mathrm{~min}$ before starting the experiment. For experiment 1 and experiment 2, a Gossen Mavolux 5032C Meter GO 4056 was used to measure the illuminance on the work surface. A factorial between-subject design was employed with two independent variables: the CRI (CRI $<80$ vs. CRI $\geq 80$ ) and CCT ( $3000 \mathrm{~K}$ vs. $6500 \mathrm{~K})$. Conditions involving LED lights with a CRI $<80$ and LED lights with a CRI $\geq 80$ were applied to evaluate the color rendition properties of the LED lights, and CCTs of $3000 \mathrm{~K}$ and $6500 \mathrm{~K}$ were applied to evaluate the objects the lights reflected off. Previous studies used an IES Rf in the range of 60-95 for fidelity and an IES Rg in the range of 80-120 for gamut [39-41]. The National Electrical Manufacturers Association (NEMA) [42] used ten levels to specify the chromaticity of solid-state lighting (2200-6500 K). The two levels for the CRI and CCT selected in this study were thus based on prior research and industry recommendations. The CRI $<80$ (LEDs A, C, E, and G) and CRI $\geq 80$ (LEDs B, D, F, and H) conditions had two levels of relative gamut area, presenting those that could saturate or de-saturate different colors. The CRI $<80$ condition had higher Rg values and the CRI $\geq 80$ condition had lower $\mathrm{Rg}$ values. To investigate the recommendation of illuminance levels, an illuminance of 300 lux was selected for experiment 1 and of 500 lux for experiment 2. The CIE $R_{a}$ is a color fidelity measure to characterize light source color rendition. It quantifies how similarly a source can render eight test color samples in comparison to a reference illuminant. The IES $R_{f}$ is a measure of color fidelity. It quantifies how similarly a source can render ninety-nine test color samples in comparison to a reference illuminant. The IES $R_{g}$ is a measure of the color gamut. It quantifies the average increase or decrease of the chroma of objects in comparison to a reference illuminant. The IES $R_{f}$ and IES $R_{g}$ combination values were used to give a detailed understanding of hue and chroma shifts in this study. $\mathrm{D}_{\mathrm{uv}}$ is the distance from the test chromaticity coordinates to the Planckian 
locus. Table 1 shows the LED lighting conditions for the experiments. Figure 2 shows the spectral power distribution of each LED light.

Table 1. Characteristics of the eight LED lighting conditions.

\begin{tabular}{cccccccc}
\hline & LED & CRI $^{\mathbf{1}}$ & & & CCT $^{\mathbf{2}}$ & Illuminance & D $_{\mathbf{u v}}$ \\
\hline & Lighting Condition & $\left.\mathbf{( R}_{\mathbf{a}}\right)$ & $\left.\mathbf{( R}_{\mathbf{f}}\right)$ & $\left.\mathbf{( R}_{\mathbf{g}}\right)$ & $\mathbf{( K )}$ & $\mathbf{( l u x )}$ & \\
\hline Experiment 1 & $\mathrm{A}$ & 79 & 83 & 103 & 3007 & 300 & -0.0149 \\
& $\mathrm{~B}$ & 83 & 83 & 100 & 3000 & 300 & 0.0066 \\
& $\mathrm{C}$ & 76 & 83 & 112 & 6495 & 300 & -0.0227 \\
& $\mathrm{D}$ & 84 & 83 & 103 & 6490 & 300 & 0.0059 \\
\hline Experiment 2 & $\mathrm{E}$ & 78 & 83 & 103 & 2995 & 500 & -0.0214 \\
& $\mathrm{~F}$ & 87 & 83 & 102 & 3010 & 500 & -0.0027 \\
& $\mathrm{G}$ & 78 & 83 & 114 & 6505 & 500 & -0.0199 \\
& $\mathrm{H}$ & 83 & 83 & 107 & 6487 & 500 & 0.0181 \\
\hline
\end{tabular}

${ }^{1} \mathrm{CRI}=$ color rendering index $;{ }^{2} \mathrm{CCT}=$ correlated color temperature.

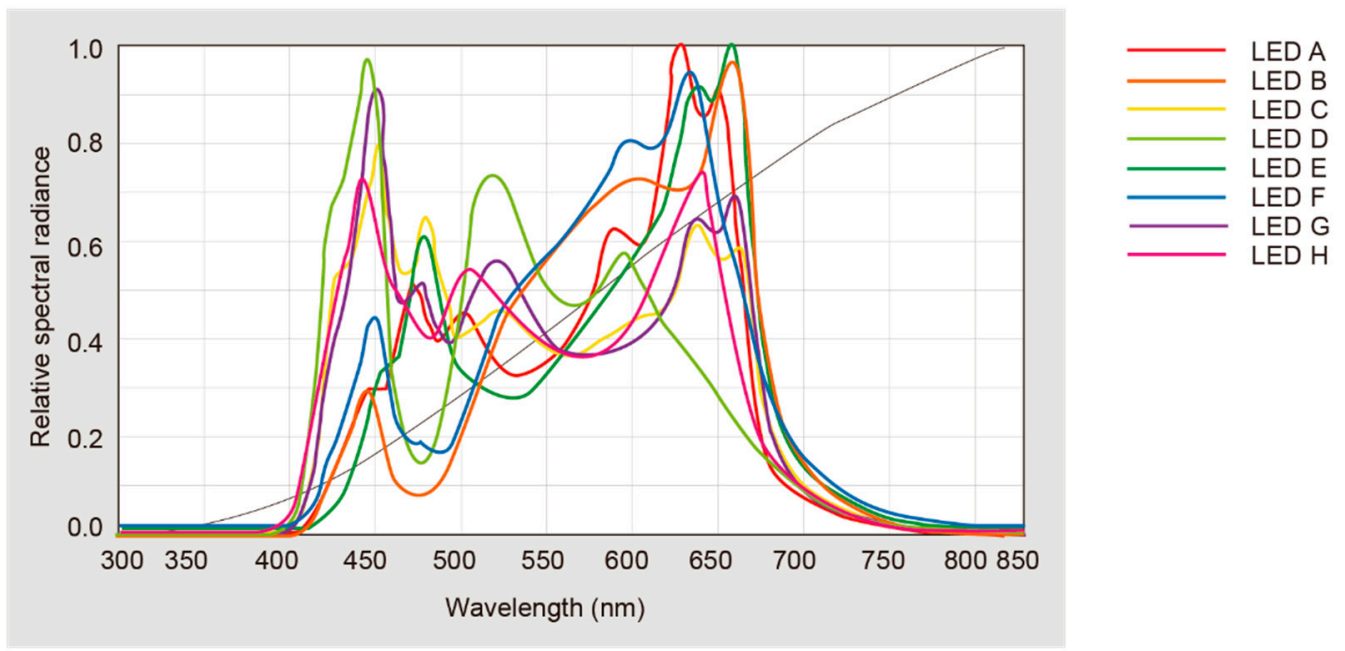

Figure 2. Relative spectral power distributions of the eight LEDs.

\subsection{Participants}

In experiment 1, 96 students (57 men, 39 women) were recruited. Their mean age was 21.73 years (standard deviation $(\mathrm{SD})=2.217$ ) from a range of $18-27$ years. In experiment 2 , 98 students ( 48 men, 50 women) were recruited. Their mean age was 21.43 years $(\mathrm{SD}=2.187)$ from a range of 18-27 years. They all had normal color perception (a dyschromatopsia test was conducted using Ishihara pseudoisochromatic plates to check this). All participants were paid approximately USD 10.

\subsection{Reading Task}

Lee et al. [43] and Hamedani et al. [44] conducted experiments in an office involving a reading task, testing whether people were able to read a text printed in 12-point Times New Roman font on an A4-sized $(210 \times 297 \mathrm{~mm})$ sheet of paper under a given illumination environment. In our study, a reading task was issued using a text in 12-point BatangChe font on an A4-sized sheet of paper. The font and size were selected from the previous studies' materials $[45,46]$. The reading task in this test was for black and white printing. Paper-based reading tasks in previous studies were designed to simulate everyday office tasks. The reading tests were selected from the Science Research Associated Reading Laboratory (SRA) materials [44]. Thus, the text was taken from the language section of Korea's College Scholastic Ability Test. Participants were asked to read the text and 
underline incorrect words for three minutes. Whether the correct words were underlined in the reading task or not was not evaluated.

\subsection{Questionnaire}

A questionnaire with 11 response sets (Q1-Q11) was developed to investigate the various aspects of user acceptance for LED office lighting [16,47,48]. Participants were asked to respond to statement prompts using a seven-point scale. A list of categories and response pairs for each question is shown in Table 2.

Table 2. Questionnaire composition.

\begin{tabular}{|c|c|c|c|}
\hline Category & Question & Statement Prompt & Response \\
\hline \multirow[t]{2}{*}{$\begin{array}{l}\text { Light } \\
\text { appearance }\end{array}$} & Q1 & Lighting in this room is ... & Dark-bright \\
\hline & Q2 & Lighting in this room feels ... & Cold-warm \\
\hline $\begin{array}{c}\text { Spatial } \\
\text { brightness }\end{array}$ & Q3 & Reading text under this lighting was ... & Dark-bright \\
\hline Preference & Q4 & $\begin{array}{l}\text { I preferred reading text under this } \\
\text { lighting. }\end{array}$ & $\begin{array}{c}\text { Strongly } \\
\text { disagree-strongly agree }\end{array}$ \\
\hline \multirow[t]{2}{*}{ Visual comfort } & Q5 & Reading text under this lighting was ... & $\begin{array}{l}\text { Uncomfortable-- } \\
\text { comfortable }\end{array}$ \\
\hline & Q6 & $\begin{array}{l}\text { I feel comfortable reading text under this } \\
\text { lighting. }\end{array}$ & $\begin{array}{c}\text { Strongly } \\
\text { disagree-strongly agree }\end{array}$ \\
\hline \multirow[t]{2}{*}{ Readability } & Q7 & Reading text under this lighting was... & Difficult-easy \\
\hline & Q8 & $\begin{array}{l}\text { Reading comprehension under this } \\
\text { lighting was effortless. }\end{array}$ & $\begin{array}{c}\text { Strongly } \\
\text { disagree-strongly agree }\end{array}$ \\
\hline \multirow[t]{2}{*}{ Satisfaction } & Q9 & Reading text under this lighting was ... & $\begin{array}{l}\text { Unsatisfactory- } \\
\text { satisfactory }\end{array}$ \\
\hline & Q10 & $\begin{array}{l}\text { I am satisfied with reading text under this } \\
\text { lighting. }\end{array}$ & $\begin{array}{c}\text { Strongly } \\
\text { disagree-strongly agree }\end{array}$ \\
\hline $\begin{array}{l}\text { Self-reported } \\
\text { productivity }\end{array}$ & Q11 & $\begin{array}{l}\text { For problem-solving under this lighting, } \\
\text { my productivity was ... }\end{array}$ & Decreased-increased \\
\hline
\end{tabular}

\subsection{Procedure}

Participants attended either experiment 1 or experiment 2 . The researcher knew the assignment of the respective subjects during the evaluation. There were no outliers. In experiment 1, two to four participants at a time were randomly allocated to one of the four lighting conditions. Upon arrival in the test room, the participants were given $3 \mathrm{~min}$ to adapt to the lighting conditions. The participants were directed by a researcher to write down their personal information (age, gender, and major) and then to complete the reading task. After finishing the reading task, participants were asked to rate the lit environment in the questionnaire. Experiment 2 was conducted using the same procedure as experiment 1.

\section{Results}

In the analysis of the data, a $2 \times 2$ factorial ANOVA with experimental factor values for the CRI and CCT were applied to calculate the main and interaction effects on dependent measures. The significance was defined as $p<0.05$. To analyze the data, SPSS 26.0 was used. Tables 3 and 4 summarize the results of the main effects of the CRI and CCT and the interaction effects of the CRI and CCT. 
Table 3. Statistical significance of the effects on evaluating the model for the questions in experiment 1.

\begin{tabular}{|c|c|c|c|c|c|}
\hline \multirow[t]{2}{*}{ Category } & \multirow[t]{2}{*}{ Questio } & \multirow[t]{2}{*}{ Response } & \multicolumn{2}{|c|}{ Main } & \multirow{2}{*}{$\begin{array}{l}\text { Two-Way } \\
\text { CRI } \times \text { CCT }\end{array}$} \\
\hline & & & CRI & CCT & \\
\hline \multirow[t]{2}{*}{ Light appearance } & Q1 & Dark-bright & $0.011 *$ & $0.000 *$ & 0.451 \\
\hline & $\mathrm{Q} 2$ & Cold-warm & 0.284 & $0.000 *$ & 0.931 \\
\hline $\begin{array}{c}\text { Spatial } \\
\text { brightness }\end{array}$ & Q3 & Dark-bright & 0.352 & $0.000 *$ & 0.406 \\
\hline Preference & Q4 & Strongly disagree-strongly agree & 0.847 & 0.513 & $0.004^{*}$ \\
\hline \multirow[t]{2}{*}{ Visual comfort } & Q5 & Uncomfortable-comfortable & 0.876 & 0.515 & $0.005 *$ \\
\hline & Q6 & Strongly disagree-strongly agree & 0.141 & 0.548 & 0.019 * \\
\hline \multirow[t]{2}{*}{ Readability } & Q7 & Difficult-easy & 0.389 & 0.258 & 0.077 \\
\hline & $\mathrm{Q} 8$ & Strongly disagree-strongly agree & 0.691 & 0.100 & 0.019 * \\
\hline \multirow[t]{2}{*}{ Satisfaction } & Q9 & Unsatisfactory-satisfactory & 0.555 & 0.967 & 0.029 * \\
\hline & Q10 & Strongly disagree-strongly agree & 0.925 & 0.457 & 0.003 * \\
\hline Productivity & Q11 & Decreased-increased & 0.901 & 0.217 & $0.002 *$ \\
\hline
\end{tabular}

Table 4. Statistical significance of the effects on evaluating the model for the questions in experiment 2.

\begin{tabular}{clcccc}
\hline Category & Question & Response & \multicolumn{2}{c}{ Main } & Two-Way \\
\hline \multirow{2}{*}{ Light appearance } & Q1 & Dark-bright & CRI & CCT & CRI $\times$ CCT \\
& & Cold-warm & 0.488 & $0.002 *$ & 0.866 \\
Spatial & Q3 & Dark-bright & 0.061 & $0.000 *$ & 0.077 \\
brightness & Q4 & Strongly disagree-strongly agree & 0.892 & $0.000 *$ & 0.923 \\
Preference & Q5 & 0.395 & 0.083 \\
Visual comfort & Q5 & Uncomfortable-comfortable & 0.876 & 0.990 & 0.658 \\
Readability & Q6 & Strongly disagree-strongly agree & 0.428 & 0.937 & 0.127 \\
& Q7 & Difficult-easy & 0.591 & 0.422 & 0.595 \\
Satisfaction & Q9 & Strongly disagree-strongly agree & 0.746 & 0.365 & 0.314 \\
Productivity & Q10 & Strongly disagree-strongly agree & 0.657 & 0.322 & 0.105 \\
& Q11 & Decreased-increased & 0.918 & 0.893 & 0.110 \\
\hline
\end{tabular}

* Indicates significance at $p<0.05$.

\subsection{Experiment 1: Illuminance 300 Lux}

\subsubsection{Light Appearance}

For Q1, the main effect of the CRI $(F(1,94)=6.703, p=0.011)$ was significant (Figure 3a). The main effect of the CCT $(F(1,94)=17.566, p<0.001)$ was significant (Figure 3b).

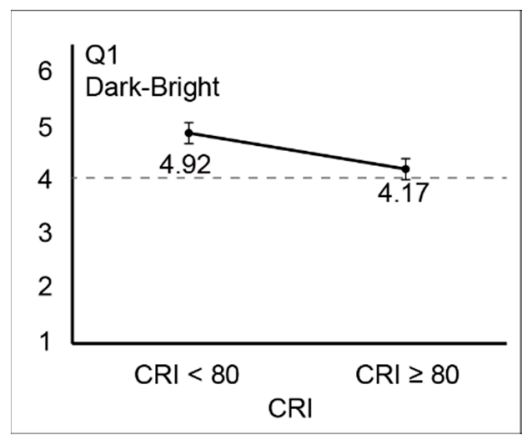

(a)

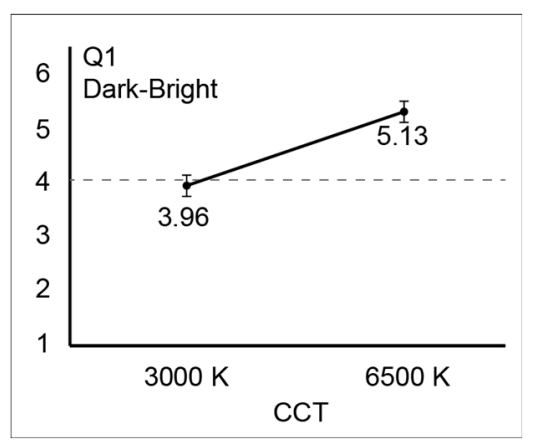

(b)

Figure 3. (a) Main effects of the CRI and (b) CCT on light appearance (Q1) in experiment 1.

For Q2, the main effect of the CCT $(F(1,94)=109.426, p<0.001)$ was significant (Figure 4). 


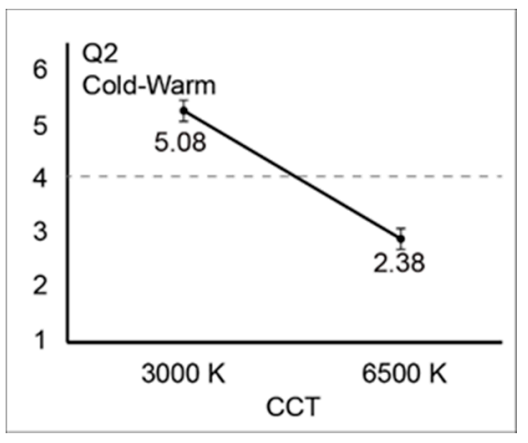

Figure 4. Main effect of the CCT on light appearance (Q2) in experiment 1.

3.1.2. Brightness, Preference, Visual Comfort, Readability, Satisfaction, and Self-Reported Productivity

Brightness. For Q3, a one-way ANOVA on the brightness perception revealed a significant effect of the CCT $(F(1,94)=14.074, p<0.001)$ (Figure 5a).

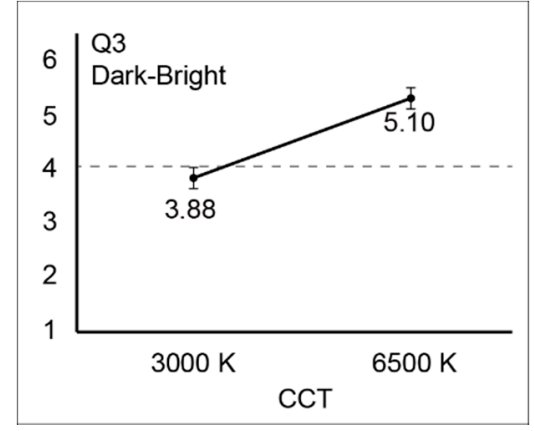

(a)

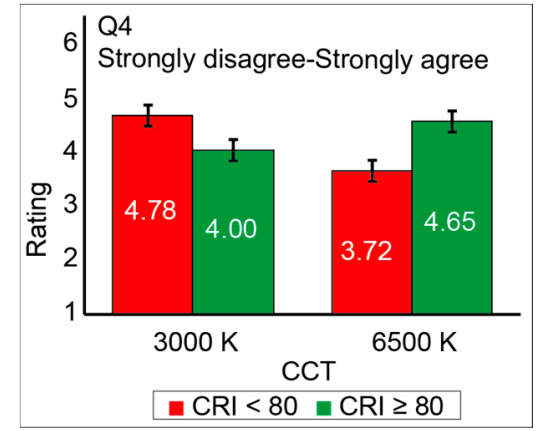

(b)

Figure 5. (a) Main effect of the CCT on brightness (Q3) and (b) interaction effect between the CRI and CCT for preference (Q4) in experiment 1.

Preference. For Q4, a two-way ANOVA showed that the interaction effect between the CRI and CCT for preference was significant $(F(1,92)=8.797, p=0.004)$ (Figure 5b).

Visual comfort. For Q5, a two-way interaction between the CRI and CCT $(F(1,92)=8.200, p=0.005)$ was significant (Figure 6a). A two-way interaction between the CRI and CCT $(F(1,92)=5.706, p=0.019)$ was also significant for Q6 (Figure 6b).

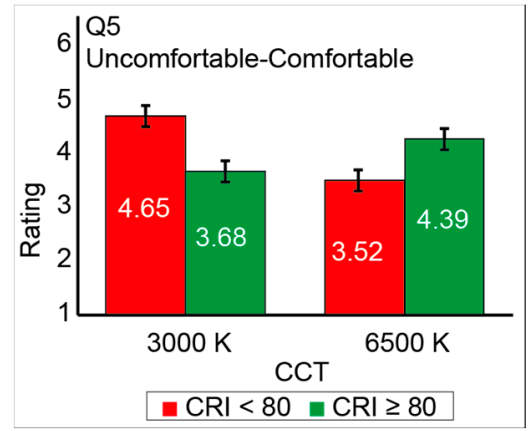

(a)

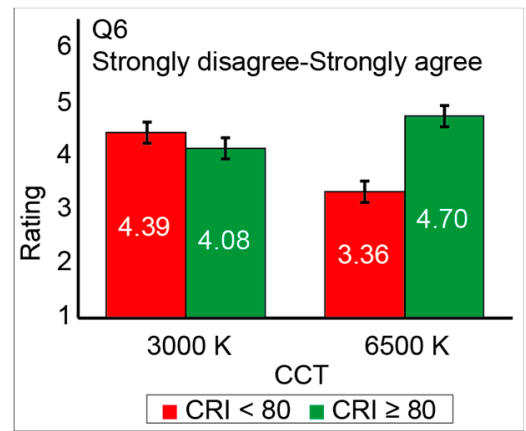

(b)

Figure 6. Interaction effects between the CRI and CCT for (a) visual comfort (Q5) and (b) visual comfort (Q6) in experiment 1. 
Readability. For Q7, a two-way interaction between the CRI and CCT $(F(1,92)=3.208$, $p=0.077$ ) was marginally significant (Figure 7a). A two-way interaction between the CRI and CCT $(F(1,92)=5.671, p=0.019)$ was also significant for Q8 (Figure $7 b$ ).

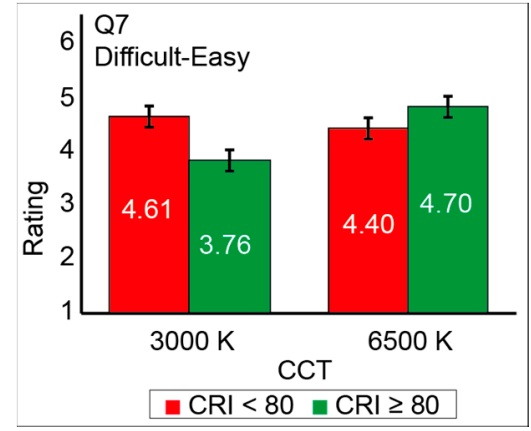

(a)

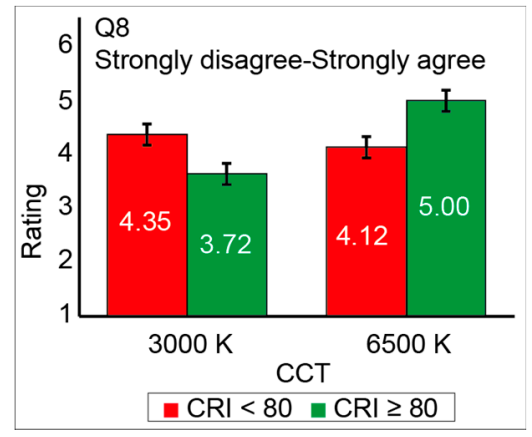

(b)

Figure 7. Interaction effects between the CRI and CCT for (a) readability (Q7) and (b) readability (Q8) in experiment 1.

Satisfaction. For Q9, a two-way interaction between the CRI and CCT $(F(1,92)=4.903$, $p=0.029$ ) was significant (Figure 8a). A two-way interaction between the CRI and CCT ( $F$ $(1,92)=9.339, p=0.003$ ) was also significant for Q10 (Figure 8b).

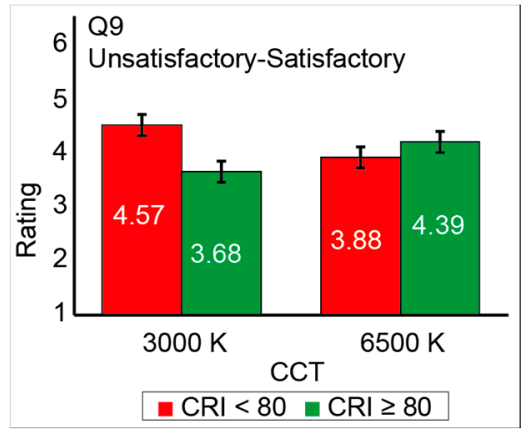

(a)

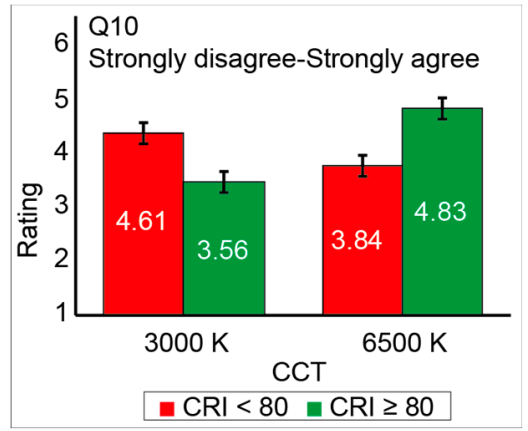

(b)

Figure 8. Interaction effects between the CRI and CCT for (a) satisfaction (Q9) and (b) satisfaction (Q10) in experiment 1.

Self-reported productivity. For Q11, a two-way ANOVA on the self-reported productivity revealed a significant interaction effect between the CRI and CCT $(F(1,92)=9.894$, $p=0.002$ ) (Figure 9).

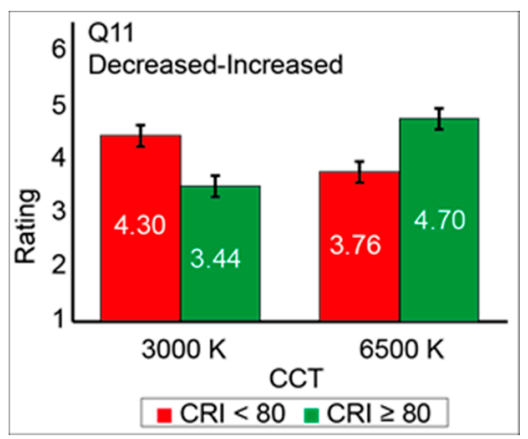

Figure 9. Interaction effect between the CRI and CCT for self-reported productivity (Q11) in experiment 1 . 
3.2. Experiment 2: Illuminance 500 Lux

3.2.1. Light Appearance

For Q1, the main effect of the CCT $(F(1,96)=9.728, p=0.002)$ was significant (Figure 10b).

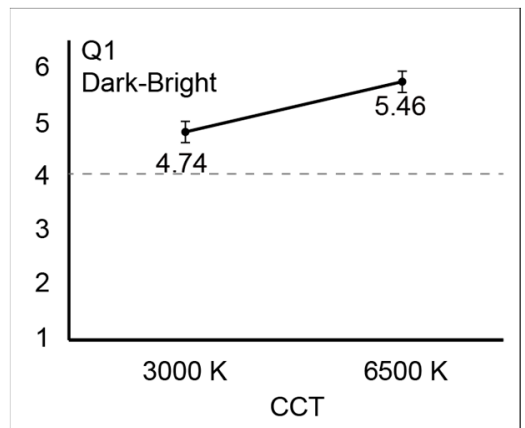

(a)

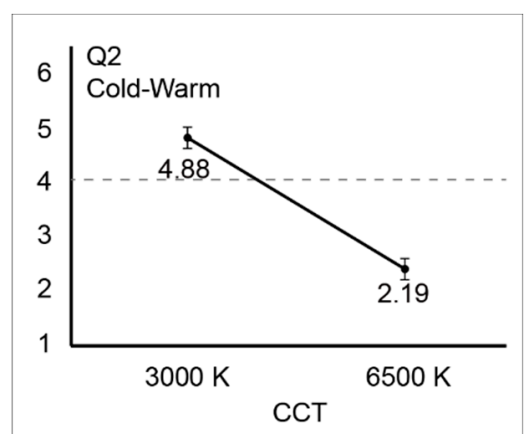

(b)

Figure 10. Main effects of the CCT on (a) light appearance (Q1) and (b) light appearance (Q2) in experiment 2.

3.2.2. Brightness, Preference, Visual Comfort, Readability, Satisfaction, and Self-Reported Productivity

Brightness. For Q3, a one-way ANOVA on the brightness perception revealed a significant effect of the CCT $(F(1,96)=15.219, p<0.001)$ (Figure 11a).

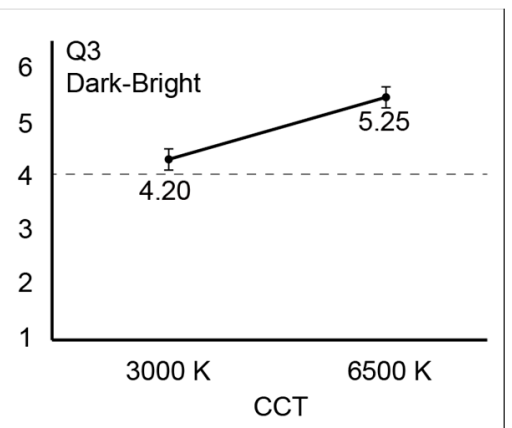

(a)

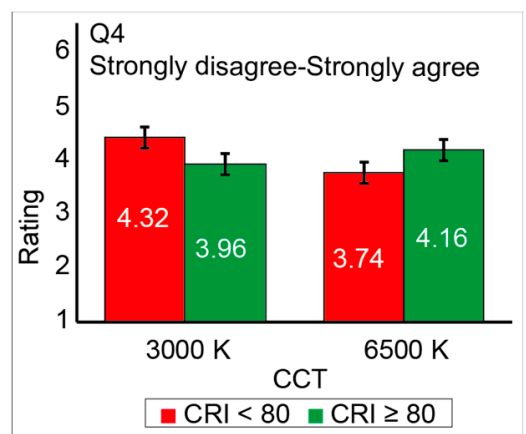

(b)

Figure 11. (a) Main effect of CCT on brightness (Q3) and (b) interaction effect between the CRI and CCT for preference (Q4) in experiment 2.

Preference. For Q4, a two-way ANOVA showed that the interaction effect between the CRI and CCT for preference was marginally significant $(F(1,94)=3.070, p=0.083)$ (Figure 11b).

Visual comfort. For both Q5 (Figure 12a) and Q6 (Figure 12b), we found no significant main effects for the CRI and CCT and no interaction effect $(\mathrm{Fs}<1)$. 


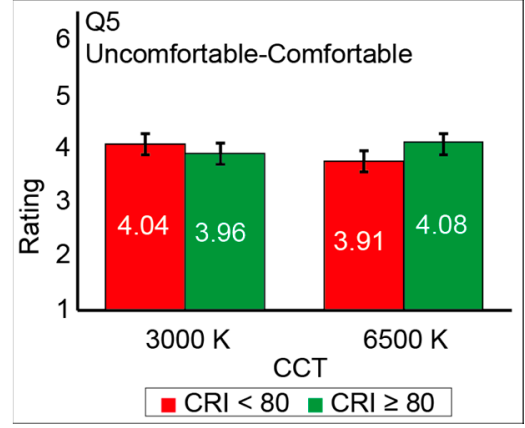

(a)

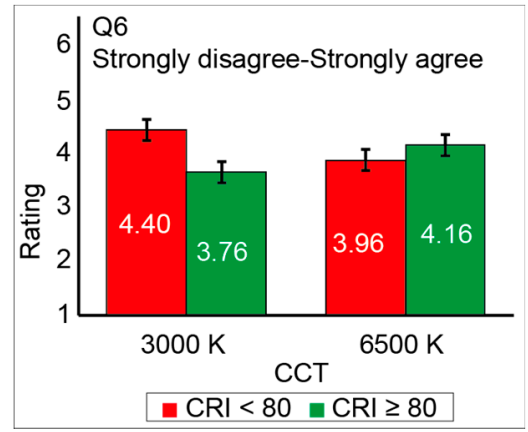

(b)

Figure 12. Interaction effects between the CRI and CCT for (a) visual comfort (Q5) and (b) visual comfort (Q6) in experiment 2.

Readability. For both Q7 (Figure 13a) and Q8 (Figure 13b), we found no significant main effects for the CRI and CCT and no interaction effect $(\mathrm{Fs}<1)$.

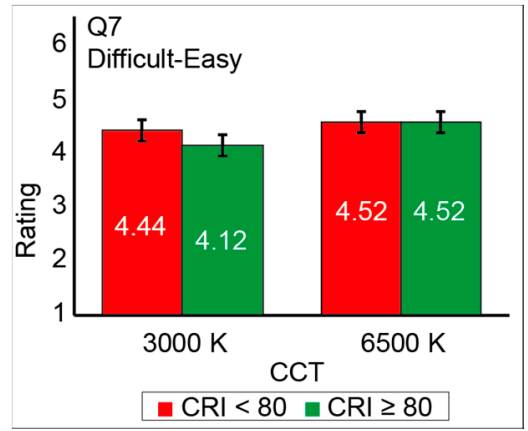

(a)

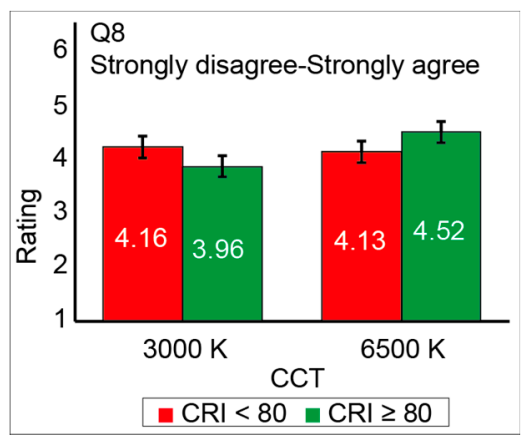

(b)

Figure 13. Interaction effects between the CRI and CCT for (a) readability (Q7) and (b) readability (Q8) in experiment 2.

Satisfaction. For both Q9 (Figure 14a) and Q10 (Figure 14b), we found no significant main effects for the CRI and CCT and no interaction effect $(\mathrm{Fs}<1)$.

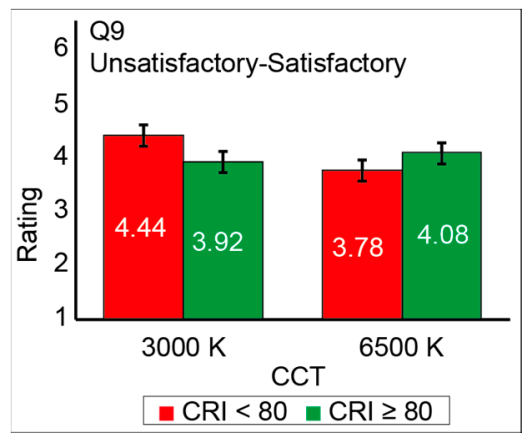

(a)

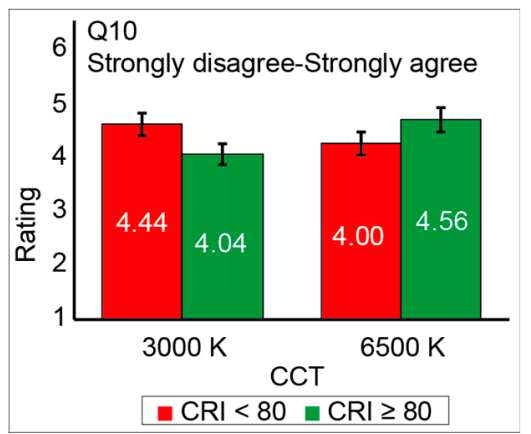

(b)

Figure 14. Interaction effects between the CRI and CCT for (a) satisfaction (Q9) and (b) satisfaction (Q10) in experiment 2.

Self-Reported Productivity. For Q11, a two-way ANOVA for the self-reported productivity revealed a significant interaction effect between the CRI and CCT $(F(1,94)=4.994$, $p=0.028$ (Figure 15). 


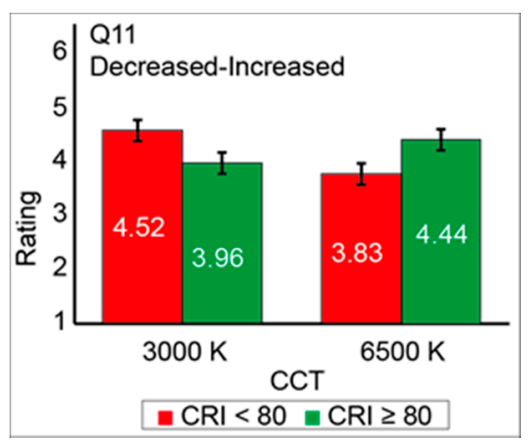

Figure 15. Interaction effect between the CRI and CCT for self-reported productivity (Q11) in experiment 2.

\section{Discussion}

In experiments 1 and 2, user acceptance was measured to investigate the appropriate color attributes for human-centric office lighting. If subjects evaluated LED lights as being acceptable, the LED light color attributes were considered suitable for HCL in offices. The user acceptance questionnaire included the categories of preference, visual comfort, readability, satisfaction, and self-productivity for the task. The finding for self-productivity for experiment 2 was nearly the same as that for experiment 1 .

The experimental results showed that the interaction effects between the CRI and CCT for user acceptance were significant. The warmer the color temperature was, the lower the CRI values were that users would accept. The cooler the color temperature was, the higher the CRI values were that users would accept. These results demonstrate that the appropriate color attributes for human-centric office lighting involve lower CRI values for warm lighting and higher CRI values for cool lighting.

For HCL in offices, the CRI $<80$ and CRI $\geq 80$ conditions were used to compare the color rendition properties of LED lights. The CCT $3000 \mathrm{~K}$ and CCT $6500 \mathrm{~K}$ conditions were specifically selected to evaluate the color appearance of LED lights. The results from experiments 1 and 2 demonstrate that the existing criterion of CRI $\geq 80$ is not useful for HCL in offices. Islam et al. [16] concluded that LED lights with a low CRI can produce higher user acceptance than LED lights with a high CRI in offices. However, the experimental results here demonstrated that LED lights with a high CRI were rated as more acceptable than LED lights with a low CRI at $6500 \mathrm{~K}$. Lighting manufacturers around the world advertise high CRI values. However, the high CRI value criterion should be considered in HCL office lighting.

Two recent studies [25,49] showed that cool LED lighting had higher acceptance than warm LED lighting for work environments. However, this study found that acceptance was weaker with a CCT of $6500 \mathrm{~K}$ than with a CCT of $3000 \mathrm{~K}$ at a CRI $<80$. This supports the finding that a high CCT does not necessarily result in high user acceptance.

The color attributes for HCL in offices were obtained by investigating the correlation between brightness perception and user acceptance. For the reading task we set, LED lights with a CRI $<80$ at $3000 \mathrm{~K}$ were rated as brighter than LED lights with a CRI $\geq 80$ at $3000 \mathrm{~K}$, and LED lights with a CRI $<80$ at $6500 \mathrm{~K}$ were rated brighter than LED lights with a CRI $\geq 80$ at $6500 \mathrm{~K}$. However, LED lights with a CRI $<80$ at $3000 \mathrm{~K}$ were rated as more acceptable than LED lights with a CRI $\geq 80$ at $3000 \mathrm{~K}$, and LED lights with a CRI $\geq 80$ at $6500 \mathrm{~K}$ were rated as more acceptable than LED lights with a CRI $<80$ at $6500 \mathrm{~K}$. The results of the analysis indicate that the increase in brightness perception was accompanied by higher acceptance at $3000 \mathrm{~K}$ but lower acceptance at $6500 \mathrm{~K}$. The level recommended for offices by the IESNA is 500 lux and that recommended by the KATS is 300 lux. It seems that offering the recommend illuminance level of 500 lux for HCL office spaces will not be accepted by users. The findings of this study confirmed that lighting for HCL in offices should be designed in consideration of the correlation between brightness perception and user acceptance. 
In experiment 1 , the lighting environment under LED lights with a CRI $<80$ at $3000 \mathrm{~K}$ was more accepted than LED lights with a CRI $\geq 80$ at $3000 \mathrm{~K}$. LED lights with a CRI $<80$ at $3000 \mathrm{~K}$ had a higher value for the IES Rg than LED lights with a CRI $\geq 80$ at $3000 \mathrm{~K}$. LED lights with a CRI $<80$ at $3000 \mathrm{~K}$ had a negative $\mathrm{D}_{\mathrm{uv}}$ value, whereas LED lights with a $\mathrm{CRI} \geq 80$ at $3000 \mathrm{~K}$ had a positive $\mathrm{D}_{\mathrm{uv}}$ value. Users were more accepting of the lighting environment under LED lights with a CRI $\geq 80$ at $6500 \mathrm{~K}$ than under LED lights with a CRI $<80$ at $6500 \mathrm{~K}$. LED lights with a CRI $\geq 80$ at $6500 \mathrm{~K}$ had a lower value for the IES $\mathrm{Rg}$ than LED lights with a CRI $<80$ at $6500 \mathrm{~K}$. LED lights with a CRI $\geq 80$ at $6500 \mathrm{~K}$ had a positive $\mathrm{D}_{\mathrm{uv}}$ value, whereas LED lights with a CRI $<80$ at $6500 \mathrm{~K}$ had a negative $\mathrm{D}_{\mathrm{uv}}$ value. Experiment 2 had the same results as experiment 1 except that the LED lights with a $\mathrm{CRI}<80$ at $3000 \mathrm{~K}$ and the LED lights with a CRI $\geq 80$ at $3000 \mathrm{~K}$ had negative $\mathrm{D}_{\mathrm{uv}}$ values. The CCT and CRI parameters were not enough to describe the color properties of LED lighting.

This study makes significant additions to several other studies. First, it contributes to the study of user acceptance by showing that the CRI and CCT are important determinants of user acceptance for HCL in offices. Previous studies on the effects of lights on user acceptance have focused on the effects of either the CRI or CCT. However, this study attempted to represent the interaction effects between CRI and CCT. The results revealed that interaction between the CRI and the CCT of LED lights has an impact on user acceptance. Future studies could explore user acceptance under various thresholds for the CRI and CCT, such as LED lights at $4000 \mathrm{~K}$ with a CRI $<80$ or $\geq 80$ or LED lights at $5000 \mathrm{~K}$ with a CRI $<80$ or $\geq 80$ [16].

In addition, this study adds to the literature on the appropriate brightness level for HCL in offices. Lights of an appropriate brightness level are necessary for users to comfortably perform office tasks. Previous studies showed the effects of either the CRI or CCT on the appropriate brightness level. This study provides evidence that manipulating the CRI and CCT of LED lights can create the appropriate brightness level for HCL in offices. Further studies could investigate the appropriate brightness levels under various thresholds for the CRI and CCT for HCL in offices.

One of the limitations of this study is that our experiments were performed in a room with a single light. In real offices, several rows of LED lights are typically installed. A blackout curtain was used to block the effects of daylight in our test room, but we cannot be sure whether daylight would increase or decrease user acceptance [50]. Since daylight is generally present in offices, more studies are needed on the effects of multiple LED lights or LED lights with daylight on user acceptance.

Finally, participants were asked to undertake our reading task within a relatively short time. Therefore, the experimental results might be different from the results obtained in a real office environment, in which the working duration is longer. Another suggestion for future studies is to investigate user acceptance in real office environments.

\section{Conclusions}

The present research investigated the interaction effects of the color rendering index (CRI) and correlated color temperature (CCT) on user acceptance and explored the proper color attributes for human-centric lighting (HCL) in offices. User acceptance is considered an important quality measure for HCL in offices. Preference, visual comfort, satisfaction, and self-reported productivity scales were employed for user acceptance assessment. The following conclusions were obtained from the experimental results:

LED lights with a CRI $<80$ at $3000 \mathrm{~K}$ were considered to be more acceptable than LED lights with a CRI $\geq 80$ at $3000 \mathrm{~K}$. By contrast, LED lights with a CRI $\geq 80$ at $6500 \mathrm{~K}$ were rated as more acceptable than LED lights with a CRI $<80$ at $6500 \mathrm{~K}$;

At a CCT of $3000 \mathrm{~K}$, LED lights with a CRI $<80$ were rated as more acceptable than LED lights with a CRI $\geq 80$, indicating that the current recommendation for a CRI $\geq 80$ is inappropriate for HCL in offices. In addition, a recommendation for the CCT is needed, as CCT is an important factor in the color attributes of LED lights; 
For brightness perception, LED lights with a CRI $<80$ were perceived to be brighter than LED lights with a CRI $\geq 80$ at both $3000 \mathrm{~K}$ and $6500 \mathrm{~K}$. The results mean that LED lights with a CRI $<80$ were perceived to be brighter than LED lights with a CRI $\geq 80$;

LED lights with a CRI $<80$ at $6500 \mathrm{~K}$ were regarded as brighter than LED lights with a CRI $\geq 80$ at $6500 \mathrm{~K}$. However, the increase in the brightness perception of LED lights with a CRI $<80$ at $6500 \mathrm{~K}$ was accompanied by lower acceptance. The analytical results showed that the LED lighting conditions were at the marginal point, where brightness perception no longer increases user acceptance. The findings indicated that the proper color attributes for HCL in offices should be determined in consideration of both user acceptance and brightness perception.

The proper color attributes for HCL in offices should have an appropriate brightness level and consider user acceptance. This study is expected to be used as a basis for developing an LED lighting system for offices that takes into account user acceptance.

Author Contributions: Designing the research, conducting the survey, analyzing the data, writingoriginal draft preparation S.L. and H.C.Y.; writing — reviewing and editing, supervision, H.C.Y. Both authors have read and agreed to the published version of the manuscript.

Funding: This research was supported by the Basic Science Research Program through the National Research Foundation of Korea (NRF-2015R1D1A1A01058577) and by the 2021 Hongik University Research Fund.

Data Availability Statement: Data sharing not applicable.

Conflicts of Interest: The authors declare no conflict of interest.

\section{References}

1. CIE. Position Statement on Non-Visual Effects of Light-Recommending Proper Light at the Proper Time, 2nd ed.; CIE Central Bureau: Vienna, Austria, 2019.

2. Houser, K.; Boyce, P.; Zeitzer, J.; Herf, M. Human-centric lighting: Myth, magic or metaphor? Light. Res. Technol. 2020, 53, 97-118. [CrossRef]

3. Berson, D.M.; Dunn, F.A.; Takao, M. Phototransduction by retinal ganglion cells that set the circadian clock. Science 2002, 295, 1070-1073. [CrossRef] [PubMed]

4. Berson, D.M. Strange vision: Ganglion cells as circadian photoreceptors. Trends Neurosci. 2003, 26, 314-320. [CrossRef]

5. IES. TM-18-18-Light and Human Health: An Overview of the Impact of Optical Radiation on Visual, Circadian, Neuroendocrine and Neurobehavioral Responses; IES: New York, NY, USA, 2018.

6. Lucas, R.J.; Peirson, S.N.; Berson, D.M.; Brown, T.M.; Cooper, H.M.; Czeisler, C.A.; Figueiro, M.G.; Gamlin, P.D.; Lockley, S.W.; O'Hagan, J.B.; et al. Measuring and using light in the melanopsin age. Trends Neurosci. 2014, 37, 1-9. [CrossRef] [PubMed]

7. CIE Central Bureau. CIE S 026:2018-CIE System for Metrology of Optical Radiation for ipRGC-Influenced Responses to Light; CIE Central Bureau: Vienna, Austria, 2018.

8. Rea, M.S.; Figueiro, M.G.; Bierman, A.; Bullough, J.D. Circadian light. J. Circadian Rhythm. 2010, 8, 2. [CrossRef] [PubMed]

9. Rea, M.S.; Figueiro, M.G.; Bierman, A.; Hamner, R. Modelling the spectral sensitivity of the human circadian system. Light. Res. Technol. 2012, 44, 386-396. [CrossRef]

10. Neberich, M.; Opferkuch, F. Standardizing Melanopic Effects of Ocular Light for Ecological Lighting Design of Nonresidential Buildings-An Overview of Current Legislation and Accompanying Scientific Studies. Sustainability 2021, 13, 5131. [CrossRef]

11. German Institute for Standardisation. DIN/TS 5031-100:2021, Optical Radiation Physics and Illuminating Engineering-Melanopic Effects of Ocular Light on Human Beings-Quantities, Symbols and Action Spectra; German Institute for Standardisation: Berlin, Germany, 2021.

12. IWBI. WELL Building Standard. LIGHT. WELL v2. Q2 2021. Available online: https://standard.wellcertified.com/well (accessed on 27 August 2021).

13. UL. Design Guidelines for Promoting Circadian Entrainment with Light for Day-Active People, 1st ed.; UL: Northbrook, IL, USA, 2020.

14. Babilon, S.; Beck, S.; Kunkel, J.; Klabes, J.; Myland, P.; Benkner, S.; Khanh, T.Q. Measurement of Circadian Effectiveness in Lighting for Office Applications. Appl. Sci. 2021, 11, 6936. [CrossRef]

15. Smolders, K.C.H.J.; De Kort, Y.A.W.; Cluitmans, P.J.M. Higher light intensity induces modulations in brain activity even during regular daytime working hours. Lighting Res. Technol. 2016, 48, 433-448. [CrossRef]

16. Islam, M.S.; Dangol, R.; Hyvärinen, M.; Bhusal, P.; Puolakka, M.; Halonen, L. User acceptance studies for LED office lighting: Lamp spectrum, spatial brightness and illuminance. Lighting Res. Technol. 2015, 47, 54-79. [CrossRef]

17. Dangol, R.; Islam, M.S.; Hyvärinen, M.; Bhushal, P.; Puolakka, M.; Halonen, L. User acceptance studies for LED office lighting: Preference, naturalness and colourfulness. Lighting Res. Technol. 2015, 47, 36-53. [CrossRef] 
18. ISO. ISO 8995-1: 2002-Lighting of Indoor Work Places-Part 1; ISO: Geneva, Switerland, 2002.

19. CIE. CIE 13.3: 1995-Method of Measuring and Specifying Colour Rendering Properties of Light Sources; CIE: Vienna, Austria, 1995.

20. CIE. CIE 15:2004-Colorimetry, 3rd ed.; CIE: Vienna, Austria, 2004.

21. IESNA. The Lighting Handbook: Reference and Application, 10th ed.; IESNA: New York, NY, USA, 2011.

22. BAuA. ASR A3.4 Beleuchtung-Technische Regel für Arbeitsstätten. Available online: https://www.baua.de/DE/Angebote/ Rechtstexte-und-Technische-Regeln/Regelwerk/ASR/ASR-A3-4.html (accessed on 5 September 2021).

23. Juslén, $\mathrm{H}$. Influence of the colour temperature of the preferred lighting level in an industrial work area devoid of daylight. Ingineria Iluminatului 2006, 8, 25-36.

24. Manav, B. An experimental study on the appraisal of the visual environment at offices in relation to colour temperature and illuminance. Build. Environ. 2007, 42, 979-983. [CrossRef]

25. Wang, Q.; Xu, H.; Zhang, F.; Wang, Z. Influence of color temperature on comfort and preference for LED indoor lighting. Optik 2017, 129, 21-29. [CrossRef]

26. CIE. CIE 224: 2017-Colour Fidelity Index for Accurate Scientific Use; CIE: Vienna, Austria, 2017.

27. IES. ANSI/IES TM-30-20-IES Method for Evaluating Light Source Color Rendition; IES: New York, NY, USA, 2020.

28. Wei, M.; Houser, K.W.; Allen, G.R.; Beers, W.W. Color preference under LEDs with diminished yellow emission. J. Illum. Eng. Soc. 2014, 10, 119-131. [CrossRef]

29. Houser, K.W.; Fotios, S.A.; Royer, M.P. A test of the S/P ratio as a correlate for brightness perception using rapid-sequential and side-by-side experimental protocols. J. Illum. Eng. Soc. 2009, 6, 119-137. [CrossRef]

30. Fotios, S.A. Lamp colour properties and apparent brightness: A review. Light. Res. Technol. 2001, 33, 163-178. [CrossRef]

31. Ohno, Y. Practical use and calculation of CCT and Duv. J. Illum. Eng. Soc. 2014, 10, 47-55. [CrossRef]

32. Ju, J.; Chen, D.; Lin, Y. Effects of correlated color temperature on spatial brightness perception. Color. Res. Appl. 2012, 37, 450-454. [CrossRef]

33. Kim, I.T.; Jang, I.H.; Choi, A.S.; Sung, M. Brightness perception of white LED lights with different correlated colour temperatures. Indoor Built Environ. 2015, 24, 500-513. [CrossRef]

34. Dikel, E.E.; Burns, G.J.; Veitch, J.A.; Mancini, S.; Newsham, G.R. Preferred chromaticity of color-tunable LED lighting. J. Illum. Eng. Soc. 2014, 10, 101-115. [CrossRef]

35. Royer, M.P.; Houser, K.W. Spatial brightness perception of trichromatic stimuli. J. Illum. Eng. Soc. 2013, 9, 89-108. [CrossRef]

36. KSA. KSA 3011-2018-Recommended Levels of Illumination; KSA: Seoul, Korea, 1998.

37. Chraibi, S.; Crommentuijn, L.; van Loenen, E.; Rosemann, A. Influence of wall luminance and uniformity on preferred task illuminance. Build. Environ. 2017, 117, 24-35. [CrossRef]

38. Chraibi, S.; Creemers, P.; Rosenkötter, C.; van Loenen, E.J.; Aries, M.B.; Rosemann, A.L. Dimming strategies for open office lighting: User experience and acceptance. Lighting Res. Technol. 2019, 51, 513-529. [CrossRef]

39. Royer, M.P.; Wilkerson, A.; Wei, M. Human perceptions of colour rendition at different chromaticities. Lighting Res. Technol. 2018, 50, 965-994. [CrossRef]

40. Royer, M.P.; Wilkerson, A.; Wei, M.; Houser, K.; Davis, R. Human perceptions of colour rendition vary with average fidelity, average gamut, and gamut shape. Lighting Res. Technol. 2017, 49, 966-991. [CrossRef]

41. Esposito, T.; Houser, K. Models of colour quality over a wide range of spectral power distributions. Lighting Res. Technol. 2019, 51, 331-352. [CrossRef]

42. NEMA. C78.377-2015-American National Standard for Electric Lamps-Specifications for the Chromaticity of Solid State Lighting (SSL) Products; NEMA: Arlington, VA, USA, 2015.

43. Lee, J.H.; Moon, J.W.; Kim, S. Analysis of occupants' visual perception to refine indoor lighting environment for office tasks. Energies 2014, 7, 4116-4139. [CrossRef]

44. Hamedani, Z.; Solgi, E.; Hine, T.; Skates, H.; Isoardi, G.; Fernando, R. Lighting for work: A study of the relationships among discomfort glare, physiological responses and visual performance. Build. Environ. 2020, 167, 106478. [CrossRef]

45. Kim, H.J.; Baik, J.K. Psychological consideration of legibility on the typeface and line spacing. Arch. Des. Res. 2009, $22,105-114$.

46. Kim, S.; Lee, K.E.; Lee, H.W. The effect of hangul font on reading speed in the computer environment. J. Ergon. Soc. Korea 2013, 32, 449-457. [CrossRef]

47. Wei, M.; Houser, K.W.; Orland, B.; Lang, D.H.; Ram, N.; Sliwinski, M.J.; Bose, M. Field study of office worker responses to fluorescent lighting of different CCT and lumen output. J. Environ. Psychol. 2014, 39, 62-76. [CrossRef]

48. Veitch, J.A.; Newsham, G.R. Lighting quality and energy-efficiency effects on task performance, mood, health, satisfaction, and comfort. J. Illum. Eng. Soc. 1998, 27, 107-129. [CrossRef]

49. Wang, M.L.; Luo, M.R. Effects of LED lighting on office work performance. In Proceedings of the 201613 th China International Forum on Solid State Lighting, Beijing, China, 15-17 November 2016; pp. 119-122.

50. Mills, P.R.; Tomkins, S.C.; Schlangen, L.J. The effect of high correlated colour temperature office lighting on employee wellbeing and work performance. J. Circadian Rhythm. 2007, 5, 2. [CrossRef] [PubMed] 